\title{
The Main Maternal and Infant Health Problems in Russia and All Over the World
}

\author{
Yuri M. Komarov
}

\begin{abstract}
Major changes in health of the population are primarely defined by mather and child health rates. A number of negative trends in mother and child health have occured last years in Russia. Two of each five registered marriages are dissolved. Each year $16 \%$ of infants are born out of wedlock, and 600,000 children lose one of their parents. From 1985 to 1991 birth rates declined 1.6 fold. $34.4 \%$ of pregnant women suffered of anemia in 1995. Each year 480,000 women die globally due to complicated pregnancy and delivery. Maternal mortality in Russia is 52.8 per 100,000 . The number of unhealthy newborns and children grows. That is why a number of Russian federal programms on maternal and child health improvement are being implemented from the year 1990 J J Epidemiol,1996; $6:$ S29-S34.
\end{abstract}

children, mothers, health, mortality, morbidity, Russia

The base characteristics of population health are such medico-demographic indexes as the size of the population, the proportion of birth- and death rates, natural increase of the population, infant mortality common morbidity of the population (including communicable and non- communicable diseases), average life expectance, the lost years of healthy life (integral indicator DALY, QALY etc)

Unfavorable trends in dynamics of the population health connected with the state of maternal and infant health protection have been noticed in Russia recently. They have been often noted in publications of sociologists, specialists on public health, scientists, in summarized documents of ministries and departments, in resolution of different congresses. These unfavorable trends are the following:

- crisis in the state of Russian family;

- breach of traditional Russian mode of people reproduction;

- sharp fall in birth rate and proportion of children in the population;

- deterioration of health in pregnant women and newborns;

- high rates of maternal and infant mortality;

- relatively failure to keep normal healthy lifestyle for a family, women and children, their nutrition, health status and physi- cal development and increasing of diseases connected with the quality of nutrition and life conditions;

- epidemic increase of diphtheria and polio; rise in morbidity rate for measles, pretties, tuberculosis, venereal and parasitic diseases;

- increase in the number of accidents, injuries and intoxications;

- rise in narcomania and toxicomania among children;

- dental caries;

- increase in the number of congenital and chronic diseases among children and teenagers resulting in early disability;

- insufficient introduction of modern diagnostic procedures, new methods of prevention and treatment;

- small attention to the aspects of psycho-social adaptation to normal life of children-invalids;

- aggravation of the problem with environmental pollution and its negative influence on growing children, insufficient providing children in areas with public health hazards with preventive measures, diagnostic and medical care and rehabilitation;

- insufficient providing women and children with new medicaments, limited output of domestic drugs for children;

Research Public Health Institute, "Med Soc Economlnform", Ministry of Health and Medical Industry of Russia, Moscow, Russia. Address for correspondence : Yuri M. Komarov, Research Public Health Institute, "Med Soc Economlnform", Ministry of Health and Medical Industry of Russia, WHO Collaborating Center, 11 Dobrolubov Str., Moscow, 12725 Russia. 
- reduction of primary health care for women and children;

- imperfect system of physicians' and their certification'

- absence of standards for quality assurance of medical care provided;

- almost absolute absence of formal licensing of medical and health activity in the field of childbearing and pediatrics;

Some of these problems are common for different countries all over the world. At the most they are expressed in regions with low social and economic status.

\section{NOW LET ME DESCRIBE SOME TRENDS IN MATERNAL AND INFANT HEALTH}

\section{Family Status:}

conjugal coefficient has been declining recently in Russia; 2 of 5 registered marriages are dissolved, more than $30 \%$ of divorces fall on young families lived less than 5 years; $16 \%$ of children are born out of wedlock. Annually about 600,000 children lose one of their parents (divorce or death). About 100,000 children are brought up at state institutions, their main contingent - "social" orphans (abandoned children, children from incomplete families and children whose parents were deprived of their parental rights). One of the family problems is cruel treatment of children.

\section{Human Reproduction and Birth rate:}

in 1985 , in Russia the birth rate was 17 per 1,000 population. In 1991 it reduced to 10.8. Since 1992 the number of people has been decreasing especially in the North-West, Central and in Volga- Viatka regions. Rates of fertility and human reproduction decline, proportion of children born by women under 20 years of age increases; the share of first-borne among newborns increases while that of second-borne and third-borne reduces.

\section{Health of Women of Fertile Age, Pregnant Women and Newborn:}

At present time women undergo more often than men psychological and emotional stress, suffer from depression and fear, take tranquilizers. The number of women smoking and abusing alcohol increases. Sexual acceleration and absence of sexual education lead to increase the number of youthful pregnant women and mothers.

A number of extragenital, gynecological and communicable diseases among women of fertile age increases. Adaptive and compensatory potentials of female organism are decreasing that causes decompensation and complications (anemia, abnormalities of delivery etc) during pregnancy and delivery. In countries with market economy complications during pregnancy and delivery account for 1 per 2,700 women; in countries with low incomes - tens times more over.

In Russia most frequently in 1995 were observed anemia
(344 per 1,000 of pregnant women and 209 per 1,000 women during and after delivery), genitourinary diseases (123 per 1,000 in 1994 and 90 per 1,000 in 1995) and gestosis (149 and 157 per 1,000 pregnant women and women in childbirth accordingly). The rate of increase of pathological changes was highest for dysfunction of thyroid gland (by 34\% in 1995 comparing to 1994), serious forms of gestosis (by $8 \%$ ) and infections during labor (by 16\%).

\section{Maternal and Infant Mortality:}

annually all over the world 480000 women die in connection with the complications of pregnancy and delivery and about 60,000 women die in connection with abortions. In Russia the level of maternal mortality is 5-10 times more the appropriate rate in developed countries $(52.8$ per 100,000$)$. One fourth of total cases of maternal mortality is associated with abortions which till now are the main mode of contraceptions (according to the world statistics data :Risk group" connected with abortions accounts for 60 million women).

The children lost their mothers at birth, die by $50 \%$ more often than those who have mothers alive. As a whole diseases of pregnancy and delivery as well as prenatal death cases account for $9 \%$ of total losses (in India - 12\%, in the Middle East - 13\%).

According to the level of infant mortality Russia is in the fourth tens among other countries. In spite of sudden fall of birth rate the level of infant mortality doesn't reduce and accounts for $17.7 \%$ in 1995 , that mainly caused by the great number of prenatal disorders (80\%), congenital abnormalities and respiratory pathology.

\section{Physical Development and Children's Nutrition:}

in the recent years the number of children with low birth weight (less than 2,500 grams) and very low birth weight (less than 1,500 grams) and delay of prenatal development (weight decline with respect to bodylength) is increasing.

According to the report of WHO General Director (document A49/4 of February 21, 1996) on nutritional problem of babies and children at an early age a high rate of insufficient and imbalance nutrition among children was to be noted: 200 million children (more than 1/3) have bad food all over the world and this number is rising.

In developing countries 56\% of children's deaths (about 6.8 million) are caused by the consequences of undernourishment. In the USA premature birth-related and low birth-related disorders were the main causes of death among black newboms and the third - among white children. In Asian nearly $60 \%$ of children have low birth-weight. Protein and calorie insufficiency plays the leading role in it. 13.8 million children of the world have eye damage caused by vitamin A deficiency.

It is determined that nearly in fourth of "health losses" among children and nearly one third of "health losses" among 
the total population will disappear if "undernourishment" is removed.

In Russia in 1995 the delay in growth and development in the structure of newborn morbidity has second place (after gypoxia) and accounts for 52 per 1,000. During the first year of life 133,765 of $1,225,339$ children (i.e. 109 per 1,000 ) have diseases of nutritional and metabolic disorders and immune deficiency. During the following years disorders of nutrition and metabolism (in the group with endocrine diseases) accounts for 2,248 per 100,000 . (2.2\%)

\section{Health Status of Children:}

the number of unhealthy children in all age groups has been growing in recent years. Among the diseases of the newborns are increasing such pathological states as hypoxia (in 1995 in comparison with 1994 - by $11 \%$ ), retardation of growth and development (by 12.5\%), hematological disorders (by 11.4\%). The total sum of infections and inflammations among newborns has grown up during this time by $36 \%$ (from 18.2 to 24.8 per 1,000). During the first year of life the leading role plays increase of pathological state and diseases caused by getting worse life conditions and adaptive potentialities of the organism. The number of injuries and intoxications has grown up by $21 \%$, infectious and parasitic diseases - by $11.8 \%$. The number of neurous and respiratory diseases, disorders of nutrition and metabolism, is increasing too (by $6.6 \%, 5.0 \%$ and $4.8 \%$ accordingly).

The prevalence of allergic diseases of lung, skin has grown up (to $15 \%$ and even to $20 \%$ among all children) sharply increase in all age groups. New terms have appeared - polyorgan allergy, syndromes of "total" allergy and of chemical hypersensitivity.

Cardiovascular diseases such as functional pathology with heart rhythm disorders, rheumatic heart disease, arterial hypertension, initial stages of atherosclerosis and ischemic heart disease have become one of the leading problems in pediatrics.

Occurrence of the gastro-duodenal and intestinal pathology, the diseases of the genito-urinary tract, of rheumatoid arthritis, obesity which belong to multifactoral heredity-caused states is rising.

Attention to be drawn to high general prevalence of anemia among children (its incomplete registration is to be noted) and growth of myopia revealed during prophylactic screening at a rate of 7 per 100 schoolchildren (that is $16 \%$ higher than the same rate in 1994), as well as the great number of malignant neoplasms, in the first place haematoblastosis $(1,567$ of $30,304,821$, or 5.2 per 100,000 children) and tumors of the brain $(461$, or 1.5 per 100,000$)$.

The growth of morbidity is followed by early chronization of pathological processes.

\section{Congenital Developmental Abnormalities (Embryopathy):}

occurrence of great congenital disorders among the newborns averaged $2.0 \%$. By the end of the first year of life their detection reaches $5 \%$. According to postmortal data developmental abnormalities among the dead infants under one year of age diagnosed in $15 \%$ of cases. In Russia the detection of congenital abnormalities among the newborns is not sufficient (2 3 times less than the data from European catalogue). Congenital abnormalities cause nearly $10 \%$ of disability and $15-20 \%$ of mortality rate among children. $10 \%$ of abnormalities are caused by environmental teratogenic factors, $10 \%$ - by chromosomic diseases and genetic mutations and $80 \%$ - by the influence of environmental factors in combination with genetic defects that increase the sensitivity of the organism to terratogenic influence. congenital heart diseases as well as diseases of intestinal and genito-urinary tract occur most frequently.

In 1995 congenital abnormalities were registered in 25.7\% of the newborns. In 1995 in comparison with 1994 their detection increased by $5 \%$ and for older age - by $15 \%$.

\section{Nervous and Mental Diseases Among Children:}

the diseases of this group are growing year by year that cause special anxiety. Many of them become apparent in prenatal period. So, steady neurological disorders as a result of hypoxemic and ischemic affection of central nervous system and intracranial hemorrhage are revealed in $10 \%$ of all newborns irrespective of their weight.

Later most of these children will have minimum brain dysfunctions (growth retardation, convultions and other states) which they keep for more than 3 years making a problem while studying at school.

One of the most important results of prenatal affections of the nervous system is infantile cerebral paralysis (ICP) whose frequency trends to grow. So, in Russia in 1995256 children per 100,000 had ICP while in 1993 - approximately 200 children.

The number of children with mental disorders is high. In 1995 they account for $2.8 \% 100,000$ children. Mental disorders of non-psychopathic character - neurosis, asthenia, specific syndromes, consequences of organic affections of CNS, mental retardation - prevail. In 1995 in Russia were registered 246,571 children with mental retardation ( 814 per 100,000 children). Psychiatrists note that $26 \%$ of children with mental retardation were born premature.

\section{Infectious Morbidity:}

according to data of Garvard Center of population and development one of the first places among the losses of health" belongs to infectious diseases. By estimates in countries with middle and low incomes nearly 8 million children die annually from 5 causes: pneumonia, diarrhea, malaria, measles and undernourishment. The analysis of 12.2 million deaths among the children under 5 years of age showed that 4 million of them 
(34\%) died from acute respiratory infections, 3.5 million (29\%) - from undernourishment, 3 million (25\%) - from diarrhea and about 2 million ( $10 \%$ and $8 \%$ ) - from measles and malaria.

It is noted that the prevalence of so called "managerial" communicable diseases - diphtheria, hoping cough, polio, measles, epidemic parotitis increased. One of the causes of this fact defects of prophylactic vaccination.

The increase of thc cases is noted both among adults and children. It's active forms in Russia in 1995 increased in the age group $0-14$ years by $14.7 \%$ as compared with figures of 1994. One third of HIV - infected persons in Russia are children.

\section{Alcoholism, Narcomania and Toxicomania:}

Children's morbidity in Russia connected with the use of alcohol and narcotic substances is increasing (in 1995 as compared with 1994 in 2.6 times, from 1.22 to 3.1 per 100,000 children of $0-14$ years of life). At most the increase was noticed both for narco- and toxicomania (2.7 and 2.8 times) and for diseases connected with narcotic abuse (2.1 times).

Invalids:

according to the report of the Ministry of Welfare in Russian Federation there are 220 thousand children-invalids $(0.4 \%)$, but these data, in the opinion of specialists are understated (in USA, as American press reports, the number of childreninvalids reaches $11 \%$ of all the children's population).

In the structure of children's disability central nervous system diseases, mental development disorders and sense-organs diseases (eyes, ears) take the leading place:

- mental retardation and psychoneurotic diseases - 30\%;

- diseases of peripheral nervous (and neuromuscular) systems 20\%;

- ear organs diseases $-17 \%$;

- eyes diseases - $16 \%$;

- tuberculosis - $6.5 \%$;

- congenital malformations $-3.3 \%$;

- therapeutic diseases $-2.2 \%$;

- injuries - $2.5 \%$;

- neoplasms - $2.5 \%$.

\section{Traumas and Accidents.}

In the developed countries accidents are main cause of children's mortality at age 1-4 years, and they strongly influence the level of children's disability. So in USA about 300,000 children with head injuries are hospitalized every year, among them 20,000 suffer from brain injuries in future. In Russia injuries and intoxications in 1995 are registered in 7,715 per 100,000 children, and this indicator is much higher than in 1994. (7.7\% of the children)

\section{The Influence of Environment.}

Occurring every where environment pollution (radiation, heavy metals' salts, xenobiotics and other antropogenious factors) influence the developing organism of fetus and infant in two ways - directly and through matemal organism. Direct influence is expressed by mutagenous effects, arrests and violations of development; by allergisation; by damage of neuroendocrinal mechanisms, and firstly, thyroid gland and thymus; by hematoligic disorders; by productive processes.

Indirect influence through maternal organism in conditioned by fact, that morbidity increase, and lowering of compensatory possibilities in pregnant women is accompanied by activation of their, conditionally - pathogenic flora, by metabolic, dystrophic and infectious - inflammatory changes - in placenta and chorion, by deficiency of feto-placental complex and perinatal hypoxia of fetus and infant. By this early starting of compensatory-defensive systems of fetus takes place - and firstly - it's hypothalamodiencephalic structures. Their excessive activation remains during all the life and shows, as different hypothalamodiencephalic syndromes, having their own peculiarities during successive critical life periods and development of posterity.

Besides, during the last years one more display of unfavorable environmental influence is registered. This is limitation of polymorphism of hereditary structural and fermental proteins accompanied by lowering of adaptive, including immune mechanisms. Most of all this, effect is revealed in children, irradiated during their antenatal development under Chernobyl catastrophe (I.Suskov, I.Tsyboulskaya). In children, born after January 1997, such changes were expressed in much less degree. However, homozygous and monoheterozygosis increase of hereditary proteins during years becomes more and more, what can be explained only by strong violations in genetic apparatus of somatic cells of women posterity, which (women) live during the long time in ecologically unfavourable conditions. This phenomenon is typical not only for radiative, but also for other long andropogynous influences.

Except indicated general, there are some specific influences of environmental factors on the developing infant's organism. So, endemic iodine deficiency in drinking water leads to delay of mental development. 25 millions children suffer from this illness.

\section{Ways of Problems Decision}

Perspective directions of further decision of problems, concerning maternity and childhood protection (MCP) - this is, first of all, the transition from the priority of secondary preventive measures to carrying out of primary prevention.

Preventive medicine must become leading. And diseases' prevention must be carried out at a family level, using genetics' achievements and from the positions of man's ecopathology.

Foreign experience shows, that the most effective measures 
for lowering neonatal and infant mortality are preventive measures: dynamical observation of pregnant women and newborn children, provision of pregnants and mothers by additional nutrition and control to check children's nutrition conditions and vitaminization of pregnant women and infants; widening of mass preventive examinations and vaccine prevention, work in kindergartens and schools; mass preventive measures of dental diseases; integration of medical and preventive medicine and widening outpatient care for children at the expense of hospital care provision reduction, purposeful training of medical and paramedical personnel, involving of auxiliary medical personnel to antenatal service, technology development of prenatal diagnostics and pharmacology of perinatal period and child's age.

For effective realization of these measures the following things are important: concentration of medical care for children in national system of full value legislative base and sufficient financing at the expense of involving of national and public funds (according to data, given by American authors, not less than $2 \%$ per capita income for persons, living in the service region).

The number of foreign authors (C.Harris; C.Miller, De Geynd et al, USA) taking into account their own experience warn of failures and inefficiency of measures, concerning mother and child health protection only at expense of using special programs even national. This is conditioned by their maority being devoted to separate diseases, age social groups. They, as a rule, are not enough coordinated, not concern all the population and are not connected with the decision of common socio-economic problems. But here such case has the negative meaning, that services of maternity and child health care is highly add, it's informational system is archaic, regional perinatology services are equipped not so well, as central, and personnel is used not fully.

Experience of amalgamation of maternal and child care services with social health centres is also negative. Here takes place widening of primary servicing of adults and reducing of preventive care for month and child. The programme has to be created in such a way, that in one packet would be represented different complex approaches to maternal and child care problems' decision/

The packets of WHO programs are created just on such principle. So, the packet "Mother-child" includes antenatal care, diagnosis and treatment of diseases, spreading by sexual way, safe childbirth, perinatal service, family planning programs, teen-age maternity and so on. Such programs are directed on the decision of $\mathrm{MCH}$ problems, as: "Protection, stimulation and support of breast feeding", "Immunization", "Preventive measures concerning violation, caused by iodine deficiency and struggle with them", "Tobacco or health" (struggle with smoking, including passive smoking), "About prevention of alcohol and drug use and struggle with them", "Women, child and AIDS (prevention, treatment, supporting infected families)", "Dangerous wast: safe destruction and struggle with risk factors for health", program, concerning the main medicine (supply, quality, low prices) and so on.

Accordingly to this principle in Russia in 1990 there was created Federal Program "Children of Russia"/Includes 6 programs: "Family planning, "Child's nutrition industry", "Children-invalids", "Children-orphans", "Chernobyl children" and "Children of the North". The following programs already function: "Safe maternity" and "Vaccine prevention". Such specific programs got federal financial support as: Perinatal centres, Transplantation of bone marrow, Children's cardiosurgery, Children's hemodialysis, Medico-genetic care, Oncohematologic diseases in children.

However, resultantivity of these programs in Russia is not yet high. For real health improvement in the country of reproductively active population and carries of country's genofund it's children - cardinal measures are needed.

This is first of all - adoption of valid maternity and child health legislation and family legislation with studying mechanisms of it's realization and ensuring state guarantees.

This is changing social policy and economic strengthening; ecological problems' decision and criminality: local wars and problem of refugees; getting a job and provision with dwelling and nutrition/

This is changing financity of all the sphere of society life, concerning families and population's reproduction, including Public health.

In our opinion health financing in Russia must make up not less than 6-8\% of GNP and be carried out at the expense of Federal and territory budgets, Obligatory insurance resources, charity and other sources of financing.

In this difficult period of reorganization of all the country's economics it is important to maintain the national system of Maternal and Child Health Care and it's priority. The State must legislatively guarantee all the kinds of medical care for children, pregnant women and women in labor. Their provision by social benefits and privileges must be done according to the contemporary standard of living and irrespective of the fact, whether these women refer to the categories of working or not working citizens.

Only by fulfilling the complex of all these condition it will become possible not only remove the centre of science's and practice's attention from the position of diseases medicine to the position of their prevention, but also really change the situation concerning ensuring protection, rearing and development of healthy generation.

\section{Sources:}

WHO documents, "International Health Statistics and Public Services Reports", materials of Congress on Pediatry, 1995; Supplement of "Russian Herald on perinatoligy and pediatry", 